\title{
Some unconventional thoughts on refining results of minimally invasive rejuvenation with HA-fillers in male patients
}

Keywords: hyaluronic acid, plasty, biological sex, psychologist, restylane, rejuvenative, correction, protuberance, nasolabial, retrogradely, aesthetic, volumization, neurovascular, psycho emotional

\section{Mini review}

This time along with presenting my own method of introducing hyaluronic acid-based fillers for volumetric plasty of the middle and lower thirds of male faces through a minimal number of punctures I would like to bring up some aspects of correct understanding of male patients' expectations that practitioners are often not fully aware of.

In the last decades a drastic shift in public perception of gender roles and biological $\operatorname{sex}^{1,2}$ has made development of a much wider range of gender identities ${ }^{3,4}$ in individuals possible. Gender identity is a personal conception of oneself as male, female or intersex, and gender role is manifested within society by observable factors such as behavior and appearance. Psychologists speak of gender as a whole complexity of individual gender identity and gender role expressions, related social interactions, public persona, personal experiences, and psycho-emotional settings. It is generally recognized in psychology that gender identity and gender role of a person may not be congruous and even more, they may not directly correspond to this person's biological sex, ${ }^{5,6}$ so practitioner's first intuitive perception of a patient may sometimes be a bit misleading.

The modern Western society accepts and tolerates a wide range of gender-variant behavior. ${ }^{7-9}$ An individual feels free to express and accentuate own gender identity. Bearing all this in mind, a cosmetologist working with male faces should be aware of own intuitive perceptions prompting the seemingly best treatment for a patient and do his/her best to understand correctly what this specific patient really wants. Furthermore, a well-known to psychologists and marketing specialists' fact that people may not be able to formulate their wishes in such a way that other people understand them correctly, should be also taken into consideration. Moreover, males often tend towards brevity of speech and too short descriptions.

Figure 1 shows the main areas of filler introduction for volumetric correction of a male patient's face. I use Juvederm Voluma, Restylane Volyme etc. for this purpose-these HA-based fillers give a maximally natural looking rejuvenative effect lasting 1-1,5 years. Filler injection in these areas allows not only to correct a tired look caused by timerelated involution of face fat compartments, ${ }^{10}$ but also to accentuate some masculine features or create a softer androgynous look according to patient's wishes. Injections should be made precisely into the fat compartment to be corrected, so the success of the procedure depends not only on the volume of the injected filler, but also on the injection point's layout and introduction method. The introduced preparation
Volume I Issue 4 - 2017

Max Adam Scherer

Department of Dermatology and cosmetology, Russia

Correspondence: Max Adam Scherer, Plastic surgeon, dermatologist, cosmetologist in private practice; Clinic of High Aesthetic Medicine; Bolshoi Karetny Pereulok, dom 24, stroenie 2; I2705I Moscow, Russia, Tel+7 (495) 508-1873, Email dr.max.adam.scherer@gmail.com

Received: August 14,2017| Published: November 24, 2017

should be modeled immediately after injection in order to ensure an even distribution of the filler and a natural looking result.

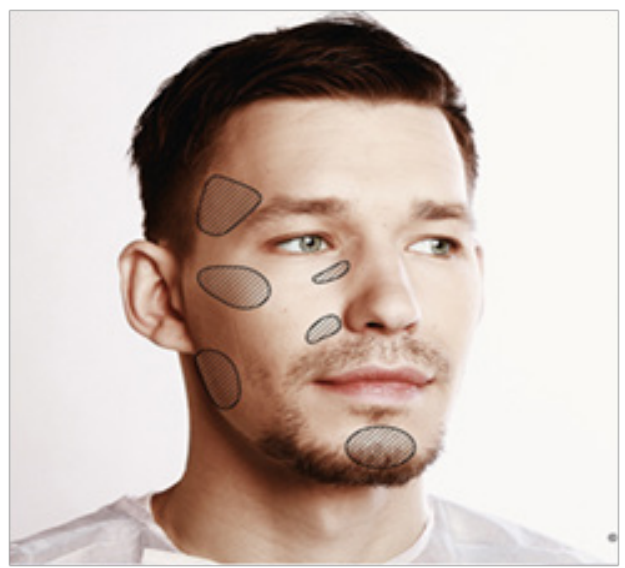

Figure I Shows the main areas of filler introduction for volumetric correction of a male patient's face.

\section{Middle and lower face third correction}

To correct these areas I use one access point in the nasolabial fold located at $2 / 3$ of its length inferiorly from the ala as shown in Figure 2. After applying topic anesthetic cream a punction for cannula introduction is made. This access point allows to accomplish correction of the nasolabial fold (retrogradely), the area around the corners of the mouth, the tear trough and the malar zone. The volume of introduced filler varies-usually it takes $2,5-3,5 \mathrm{ml}$ to correct one side. The advantage of this method is that it allows achieving a vivid rejuvenative result using only one puncture per side. Nevertheless this method requires a very good knowledge of the topographic anatomy of fat compartments, so that incorrect placement of the preparation can be avoided. Caution should be also taken to avoid injuring certain neurovascular structures, ${ }^{11}$ for example, facial nerve branches that innervate the area around corners of the mouth. 


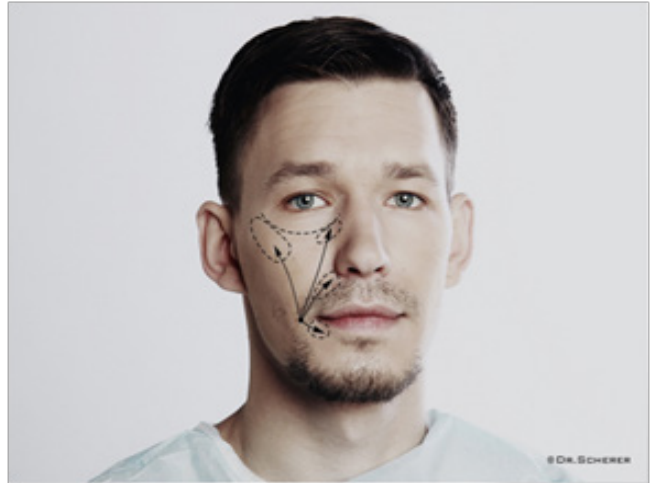

Figure $\mathbf{2}$ To correct these areas I use one access point in the nasolabial fold located at $2 / 3$ of its length inferiorly from the ala.

\section{Angles of the mandible and mental area correction}

The main task in correcting these areas with the use of volumetric fillers is to restore, accentuate or slightly change the mandible outline. Correction of angles of the mandible is made through a perpendicular puncture that is carried through all soft tissue layers down to the bone. Upon reaching the bone surface an aspiration test is made to make sure that the filler will not be injected into a blood vessel. After that 1 , $5-2 \mathrm{ml}$ of the preparation are very slowly (important!) introduced into this area. A very slow introduction of the preparation allows a more even distribution and ensures symmetry. If a follow-up examination reveals insufficient correction, an extra amount of filler can be injected two weeks after the first procedure. It should be held in mind that Volumization of angles of the mandible accentuates masculinity.

Correction of a male chin is made using 2 symmetrically placed injection points, the location of which is defined arbitrarily within projection of the mental protuberance through palpation of the latter. The injection is made at a right angle. $0,5-1 \mathrm{ml}$ of filler is introduced in a direction towards the bony edge of the mental protuberance on every side. After that the injected preparation is modeled. I use to fixate the mental area with surgical strips for the first 24 hours in order to prevent preparation displacement.

\section{Nasolabial fold correction}

If the patient wants to maintain or even accentuate a masculine look, the nasolabial fold should be left untouched or should be corrected not more than to half of its depth. The correction is made in bolus technique in the upper third or in the upper and middle thirds of the fold.

\section{Conclusion}

I would like to note that besides good procedure techniques which are essential for building up a sound expertise, development of the skill to understand what patients really want and of a creative aesthetic vision will bring the ability to achieve not just "good results", but a deeply satisfying outcome for every patient. Here awareness and consideration of the above mentioned issues plays an important role, especially in treatment of male patients.

\section{Acknowledgements}

None.

\section{Conflict of interest}

The author declares no conflict of interest.

\section{References}

1. Spence JT. Gender identity and its implications for the concepts of masculinity and femininity. Nebr Symp Motiv. 1984;32(1):59-95.

2. Schnabel L. Gender and homosexuality attitudes across religious groups from the 1970s to 2014: similarity distinction and adaptation. Soc Sci Res. $2016 ; 55: 31-47$

3. Richards C, Bouman WP, Seal L, et al. Non-binary or genderqueer genders. Int Rev Psychiatry. 2016;28(1):95-102.

4. Kuper LE, Nussbaum R, Mustauski B. Exploring the diversity of gender and sexual orientation identities in an online sample of transgender individuals. J Sex Res. 2012;49(2-3):244-254.

5. Pedersen W, Kristiansen HW. Homosexual experience, desire and identity among young adults. J Homosex. 2008;54(1-2):68-102.

6. Eliason MJ, Streed CG. Choosing something else as a sexual identity: evaluating response options on the national health interview survey. $L G B T$ Health. 2017;4(5):376-379.

7. Herek GM. Legal recognition of same-sex relationships in the United States: a social science perspective. Am Psychol. 2006;61(6):607-621.

8. Doderer YP. LGBTQs in the city: queering urban space. Int J Urban Reg Res. 2011;35(2):431-436.

9. Doyle CM, Rees AM, Titus TL. Perceptions of same-sex relationships and marriage as gender role violations: an examination of gendered expectations (sexism). J Homosex. 2015;62(11):1576-1598.

10. Scherer MA. Specific aspects of a combined approach to male face correction: botulinum toxin A and volumetric fillers. J Cosmet Dermatol. 2016;15(4):566-574.

11. Seckel BR. Facial danger zones: Avoiding nerve injury in facial plastic surgery. 2nd ed. New York, USA: Thieme Medical Publishers; 2010. 52 p. 